\title{
METADATA, ARSIP, DAN INFORMASI: SUMBANGAN STANDAR- STANDAR KEARSIPAN TERHADAP KERANGKA DAN MODEL KERJASAMA KEILMUAN BIDANG-BIDANG SERUMPUN
}

\author{
Raistiwar Pratama* \\ Arsip Nasional Republik Indonesia \\ *Korespondensi: pratama.raistiwar@gmail.com
}

\begin{abstract}
Since the end of XIX century when for the very first time the archival principles of arrangement and description were outlined until ICA have published their first international standard commonly known as ISAD-G which defines its 26 elements of archival description and followed afterwards by series of archival standards (ISAARCPF, ISDIAH, and ISDF) in 1990's and 2000's. These elements of description are similar to metadata elements. As the metadata elements of Dublin Core, for example, that have been released in the mid of 1990's and then later on was adopted by ISO 15836-1:2017 and ISO 15836-2:2019. This article describes the similarities among both elements, the elements of description and the elements of metadata, including the ICA's latest archival standard (RiC) and by using paradigm of integration-interconnection and three model of discplinary cooperation (multidisciplinary, interdisciplinary, and transdisciplinary) according to Amin Abdullah. Besides reading closely towards the literary sources including the published standards released by ICA and ISO, the writer also does the same things towards various archival standards published by several national archives. These are some of the contribution of archival science and archival standards in order to open the chance of having equal cooperation and seeing the possibilities of having cooperation among its three stages.
\end{abstract}

\begin{abstract}
ABSTRAK
Apa yang Ilmu Kearsipan rumuskan sebagai prinsip-prinsip pengolahan arsip sejak abad XIX hingga rilis standar kearsipan ISAD-G keluaran ICA yang merumuskan 26 elemen deskripsi, lalu secara berurutan terbit ISAAR, ISDIAH, dan ISDF sepanjang dasawarsa 1990 dan 2000 merupakan sesuatu serupa elemen metadata. Seperti rumusan 15 elemen metadata Dublin Core yang rilis pada medio 1990-an dan diadopsi menjadi ISO 15836-1:2017 dan ISO 15836-2:2019. Tulisan ini menelisik keserupaan elemen-elemen dalam deskripsi dan metadata, termasuk standar kearsipan terbaru keluaran ICA, dan dengan menggunakan paradigma integrasiinterkoneksi dan tiga model kerjasama keilmuan (multidisipliner, interdisipliner, dan transdisipliner) menurut Amin Abdullah. Selain tinjauan pustaka terhadap standar kearsipan keluaran ICA dan ISO, tulisan ini juga mendasarkan pembacaannya pada standar kearsipan keluaran arsip nasional beberapa negara. Inilah sumbangan ilmu dan standar kearsipan untuk membuka peluang kerjasama bidang-bidang serumpun dan melihat kemungkinan ketiga model kerjasama.
\end{abstract}

Keywords: Metadata; Records; Information; Archival standards

\section{PENDAHULUAN: MEMUNGKINKAN KERJASAMA KEILMUAN}

Pada akhir Mei 2021, Pusat Data dan Dokumentasi Ilmiah Lembaga Ilmu Pengetahuan Indonesia (PDDI LIPI) menggelar webinar bertemakan Research Data Services by Information Professionals. Webinar ketiga ini merupakan salah satu dari rangkaian webinar bertemakan Research Data Management (RDM) yang secara berkala PDDI LIPI adakan. Waktu itu, tepatnya pada 28 Mei 2021, hadir Andrew Cox sebagai narasumber. Cox, Pengajar Information School di The University of Sheffield Inggris, menguraikan kerangka keilmuan Library and Information Science (LIS) untuk pengelolaan data riset. Pada akhir setiap dari delapan bagian, Cox membuka ruang tanya jawab. Pada akhir bagian kedua penulis bertanya: "What is the relation between records, information, and data? What do these three have in common actually?" Tanpa harus membeda-bedakan dan bersemangatkan kerjasama dengan bidang-bidang serumpun, Cox 
menjawab lugas sambil menegaskan apa yang telah dia paparkan di bagian sebelumnya: "What is the relation between data, information, and knowledge? I think data is the raw material from which ultimately knowledge is created. As I said we can not generalize how that can happen because different discipline use data in a different way. They have a different relation with data. Sometimes data is created with hypothesis in mind. So it is very deductive way of looking your relationship between data and knowledge. Data is something to explore to create knowledge." Untuk beberapa hal, menurut Cox, data serupa dengan arsip meskipun tidak berarti sebaliknya namun jelas keduanya saling terhubung. Arsip yang publik kenal sebagai "historical documents" dan "government records"; serta mencakup "images", "digitised photos/born digital photos", dan "moving images" merupakan beberapa contoh data yang Cox kemukakan.

Di Indonesia, paradigma integrasi-interkoneksi (Interkon) telah Amin Abdullah kembangkan sejak awal dasawarsa 2000 untuk menjelaskan sesuatu secara tuntas tanpa sekat-sekat sempit salah satu bidang ilmu atau sebisa mungkin menghindari kepicikan penilaian kerangka pemikiran suatu ilmu terhadap ilmu lain. Kedudukan setiap ilmu dalam Interkon begitu setara. Hanya kesetaraan yang yang bisa memungkinkan terjadinya kerjasama. Dua puluh tahun kemudian, Abdullah mengembangkan Interkon menjadi kerangka model kerjasama disiplin. Alih-alih merupakan pilihan, ketiga model tersebut merupakan keadaan yang bertahap sejak multidisiplin, interdisiplin, hingga transdisiplin.

Sebegitu kuatnya pengaruh teknologi dan informasi, ICA melalui komitenya menyusun suatu standar kearsipan yang menyempurnakan keempat standar (ISAD-G, ISAAR-CPF, ISDIAH, dan ISDF) sebelumnya. Sekalipun sepintas berbeda dan beragam, standar-standar kearsipan berbicara dengan "bahasa yang sama". Bahasa yang tidak hanya dimengerti sesama standar kearsipan namun juga dengan bidang-bidang serumpun seperti museuologi, filologi, ilmu perpustakaan, ilmu dokumentasi, ilmu informasi, ilmu komunikasi, dan sains data; bahkan di luar bidang-bidang serumpun seperti dengan ilmu sejarah, antropologi, sosiologi, dan ekonomi.

Tulisan ini menelisik keserupaan elemen deskripsi setiap standar kearsipan dengan elemen metadata setiap standar dokumentasi informasi. Elemen keduanya merupakan bahasa yang mempersatukan keragaman entitas atau sekurang-kurangnya atribut atau properti. Tanpa keduanya, perubahan medium, peralihan sistem, perbedaan sistem informasi, dan keragaman aplikasi; tidak dapat "berbicara". Kesamaan keduanya yang paling kentara adalah perhatian yang diarahkan pada isi atau konten, bukan semata pada tampilan dan perantara.

\section{METODE}

Penulis menerapkan metode tinjauan pustaka terhadap standar kearsipan keluaran ICA, ISO, asosiasi profesi, dan lembaga kearsipan nasional, serta wawancara terhadap arsiparis dan pranata komputer ANRI yang terlibat dalam penyusunan standar deskripsi arsip statis, anggota Komite Teknis 01-03 Kearsipan, dan anggota Komite Teknis 01-05 Dokumentasi dan Informasi. Kemudian penulis membandingkan elemen-elemen yang Deskripsi dan Metadata kandung.

\section{HASIL DAN BAHASAN: DARI GRONINGEN KE JENEWA LEWAT PARIS}

Berikut merupakan hasil penelitian yang embrionya telah penulis semai sejak 2015 ketika mulai mengkaji Handleiding voor Het Ordenen en Beschrijven van Archieven atau Dutch Manual, standar kearsipan modern pertama di dunia. Lalu penulis lanjutkan ketika menyusun tesis magister dengan membaca standar-standar kearsipan keluaran ICA dan lembaga kearsipan nasional berbagai negara. Pada akhir 2017, penulis mulai aktif terlibat sebagai anggota Komite Teknis 0105 Dokumentasi dan Informasi. Hingga pada 2019, penulis memimpin Komite Teknis 01-03 Kearsipan yang menerjemahkan ISO 23018-:2017 Metadata for Records dan ISO 30301:2019 Management Systems for Records. 
Penulis yakini bahwa alih-alih keterputusan dan pembaharuan, standar-standar kearsipan keluaran berbagai lembaga profesi internasional, lembaga pembakuan internasional, dan lembaga kearsipan nasional rilis untuk melestarikan prinsip-prinsip kearsipan, terutama prinsip kembar atau dwitunggal pertama: asal-usul dan aturan asli. Standar-standar kearsipan tersebut merawat dan menyesuaikan. Fungsi pengarsipan jelas lebih langgeng daripada struktur kelembagaan pencipta arsip. Apa yang sejatinya terjadi adalah perubahan dan kesinambungan.

\subsection{Elemen-elemen deskripsi: Dari Dutch Manual ke ISAD-G}

Sejak akhir abad XIX, tepatnya ketika Dutch Manual edisi pertama pada 1898, istilah deskripsi (description) mengemuka bersamaan dengan penataan (arrangement). Belakangan setidaknya di kalangan arsiparis lebih dikenal istilah pengolahan untuk kedua kerja metodis tersebut. Sebegitu besar pengaruhnya, Theodore Schelenberg dan Hilary Jenkinson menyatakan Dutch Manual sebagai "a bible for modern archivists" (Barritt 1993; Cook 1997). Pada peringatan jelang seabad Dutch Manual pada 1997, Terry Cook menyatakan bahwa "The importance of the Dutch Manual rests on its codification of European archival theory and its enunciation of a methodology for treating archives". Sepuluh tahun kemudian-lebih dari seabad setelah kelahirannya—John Ridener (2007: 175) pun masih menyatakan bahwa Dutch Manual merupakan “... the first single work of archival theory and the basis for much contemporary practice all over the world".

Tujuh tahun kemudian, Hans Kaiser menyusun terjemahan berbahasa Jerman, termasuk pembaharuan isi. Setahun kemudian setelah terbit edisi Jerman, Joseph Cuvelier dan Henri Stein menyusun terjemahan berbahasa Prancis. Menyusul Giovanni Vittani dan Giuseppe Bonelli menyusun terjemahan berbahasa Italia. Pada 1912, berdasarkan pada edisi Prancis terbit terjemahan berbahasa Bulgaria oleh Christo Tachalov dan Dimitri Pop Ilev. Secara sebagian pada 1925 dan 1931, terbit terjemahan berbahasa Rusia. Duapuluh dua tahun setelah terbit edisi pertama, terbit edisi kedua, namun tanpa mengikutsertakan pembaharuan pada edisi Jerman limabelas tahun sebelumnya. Penerbitan edisi revisi pada 1938 tidak terlaksana.

Pada 1940, Arthur Leavitt pun menyusun terjemahan berbahasa Inggris, terutama merujuk pada edisi kedua 1920 dan terjemahan berbahasa Perancis, Jerman, dan Belanda. Manual for the Arrangement and Description of Archives, begitu judul terjemahan Leavitt. Beberapa tahun sebelum 1940 di Amerika Serikat, Arnold J. F van Laer dan Waldo H. Leland sudah memperkenalkan bagian-bagian tertentu darinya, bahkan kemudian Leavitt acapkali kirimkan hasil terjemahannya bab per bab kepada van Laer untuk kesesuaian makna, istilah, dan lema hingga 30 September 1939. Van Laer jugalah yang sarankan untuk menyadur Dutch Manual sesuai konteks Amerika (Barritt 1993). Bermula dari edisi Amerika itulah, terbit terjemahan berbahasa Tionghoa pada 1959. Setahun kemudian terbit edisi Bulgaria berbahasa Portugis oleh Adolpho Wanderley, utamanya berdasarkan edisi berbahasa Inggris, dan tigabelas tahun kemudian terbit edisi revisi. Keduanya berjudul Manual de arranjo e descrição de arquivos (Horsman et.al. 1998/2003). Hingga kini belum penulis dapati terjemahan Dutch Manual berbahasa Indonesia, walaupun pengaruhnya cukup terasa, terutama melalui pendirian Landsarchief pada 1892 di Hindia Belanda. Pada 2003 terbit kembali Dutch Manual berbahasa Inggris karya Leavitt lagi-lagi oleh Society of American Archivists (SAA).

Dutch Manual terdiri atas enam bab: Onstaan en indeeling van archiefdepots (1-14), Het sorteeren der archiefstukken (15-36), Het beschrijven der archiefstukken (37-49), Het ineenzetten van den inventaris (50-69), Verdere beschrijvingsmaatregelen (70-83), dan Over het conventioneel gebruik van eenige termen en teekens (84-100) (Muller et.al. 1940, 10). Horsman et.al. (1998/ 2003) menyatakan bahwa sumbangan terbaik Dutch Manual adalah mendefinisikan fonds yang dikaitkan dengan arsip dan fungsi yang menciptakannya dan arsiparis harus cermat memahami 
batas-batas dan struktur suatu arsip, serta konteks awalnya. Sebagaimana terdapat pada Bagian 1, 2, 15, dan 16. Terkait penataan, terdapat pernyataan pada Bagian 15 "bahwa arsip harus secara sistematis tertata, sesuai pengarsipan semasa dinamisnya, bukan hanya bentuk organisasinya. Bagian 16 (Muller [et.al.], 1940: 52 - 59) merupakan pokok bahasan yang lebih mengutamakan struktur arsip daripada struktur organisasi karena pada dasarnya struktur arsip secara umum dan luas membentuk struktur organisasi, bukan sebaliknya. Adapun tentang description, tercantum pada Bagian 37 dan 50 bahwa "Sarana bantu temu kembali berupa inventaris merupakan tampilan berkas bukan lembaran-lembaran terpisah".

Demikianlah keseratus bagian dalam Dutch Manual yang penulis coba rangkum dan cuplik beberapa bagian yang penulis anggap mewakili isinya. Nyaris dua abad kemudian setelah terbit Dutch Manual dan hampir setengah abad setelah ICA berdiri, terbit pada 1994 standar kearsipan internasional pertama bertajuk General International Standar for Archival Description (ISAD-G). Sejak 2000, setelah terbit edisi kedua, dasar-dasar suatu standar kearsipan dan prinsipnya mulai praktisi kearsipan kenal. Keduapuluh enam elemen deskripsi memastikan arsip sebagai entitas dapat diakses, sekalipun medium, format, dan bentuknya beragam serta pencipta telah mengakhiri kerja kelembagaannya; serta merupakan bagian dari tujuh area informasi deskriptif.

Ketujuh area tersebut terdiri atas:

1. Pernyataan identitas (identity statement);

2. konteks (context);

3. struktur dan konten (content and structure);

4. persyaratan akses dan penggunaan (condition of access and use);

5. bahan-bahan terkait (allied materials);

6. catatan (note); dan

7. kendali deskripsi (description control).

Dua area pertama memuat enam elemen deskripsi mendasar. Sementara keduapuluh elemen lainnya adalah tambahan (optional). Mengapa keenam elemen pertama tersebut begitu penting? Oleh karena mendasar (essential) untuk pertukaran internasional suatu informasi deskriptif (international exchange of descriptive information). Keenam elemen tersebut antara lain:

1. Kode referensi (reference code):

2. judul (title);

3. pencipta (creator);

4. tanda waktu (date);

5. perluasan unit deskripsi (extent of the unit of description); dan

6. tingkat deskripsi (level of description).

Sarana bantu temu kembali baik berupa daftar maupun inventaris harus mencantumkan keenam elemen tersebut. Adapun keduapuluh enam elemen hanya tercantum dalam inventaris sebagai bagian pendahuluannya. Keduapuluh elemen tersebut antara lain:

1. Sejarah administratif/biografi (administrative/biographical history);

2. sejarah arsip (archival history);

3. asal akuisisi atau transfer (immediate sourcec of acquisition or transfer);

4. ruang lingkup dan konten (scope and content);

5. informasi penilaian dan penyusutan (appraisal, destruction, and scheduling information);

6. penambahan (accruals);

7. sistem penataan (system of arrangement);

8. persyaratan akses (condition governing access);

9. persyaratan reproduksi (condition governing reproduction); 
10. bahasa (language/scriptis of material);

11. persyaratan teknis dan karakter fisik (physical characteristic and technical requirements);

12. sarana bantu temu kembali (finding aids);

13. keberadaan dan lokasi arsip semula (existence and location of originals);

14. keberadaan dan lokasi arsip kopi (existence and location of copies);

15. unit deskripsi terkait (related units of description);

16. catatan terbitan (publication note);

17. catatan (note);

18. catatan arsiparis (archivist's note);

19. aturan atau konvensi (rules or conventions); dan

20. tanda waktu deskripsi (date[s] of description).

Sekalipun tambahan, keduapuluh elemen tersebut terkait erat dengan keenam elemen mendasar. Misalnya, pencipta dan perluasan unit deskripsi terkait dengan sejarah administratif, sejarah arsip, sarana bantu temu kembali, dan unit deskripsi terkait. Mengapa tambahan? Oleh karena keduapuluh elemen tersebut dapat saling menggantikan, bahkan digantikan salah satu atau dua dari enam elemen mendasar.

\subsection{Elemen-elemen metadata: Dari Dublin Core ke ISO 15836}

Semula pada 1995 terdapat tiga belas elemen, lalu kini telah bertambah menjadi lima belas elemen, demikian kiprah Dublin Core Metadata Initiative (DCMI) merumuskan Dublin Core Metadata Element Sets (DCMES) sebagai standar metadata deskripsi sumber daya lintas domain yang memungkinkan interoperabilitas. Kelima belas elemen tersebut juga disebut, sebagaimana kata sifat yang melengkapinya, sebagai elemen inti yang mencakup:

1. Judul (title);

2. pencipta (creator);

3. subjek (subject);

4. deskripsi (description);

5. penerbit (publisher);

6. kontributor (contributor);

7. tanda waktu (date);

8. tipe (type);

9. format;

10. pengenal (identifier);

11. sumber daya (source);

12. bahasa (language);

13. relasi (relation);

14. cakupan (coverage); dan

15. hak (rights).

Metadata atau, lebih lengkapnya, metadata deskriptif adalah "data terstruktur tentang segalanya yang bisa dinamai". Metadata pertama kali mengemuka pada medio dasawarsa 1990-an. "Segalanya" dapat mencakup laman, buku, artikel jurnal, citra, lagu, produk, proses, orang dan kegiatannya, data riset, konsep, dan layanan. Kelak kelimabelas elemen metadata tersebut menjadi ISO 15836 yang telah rilis dua kali pada 2003 dan 2017/2019, serta menaungi properti dan kelas (https://dublincore.org/resources/metadata-basics/retrieved 12 September 2021).

Lalu apakah metadata tersebut begitu saja serupa dengan metadata arsip? Menurut ISO 23081-1:2017, metadata arsip (metadata for records) adalah "informasi terstruktur atau semiterstruktur yang memungkinkan penciptaan, pengelolaan, dan penggunaan arsip sepanjang waktu 
serta di dalam atau lintas domain (...through time and within and and across domains)". Metadata arsip justru tidak merumuskan apa saja elemen-elemen yang melingkupinya, namun memberikan "tanda waktu" kapan metadata tersebut digunakan. Apakah diletakkan ketika "tangkapan arsip" (at the point of record capture) dan/atau setelah "tangkapan arsip" (after record capture). Sebagaimana arsip itu sendiri, perumusan apa saja elemen metadata tersebut berdasarkan pada kebutuhan bisnis (businees needs), lingkungan peraturan (the regulatory environments), dan risiko yang memengaruhi operasi bisnis (risks affecting business operations). Setidaknya terdapat tiga perspektif yang berbeda dan saling melengkapi untuk merumuskan apa saja elemen metadata yang diperlukan, yaitu bisnis, pengelolaan arsip, dan penggunaan di dalam atau di luar konteks bisnis penciptaan arsip. Demikianlah, metadata arsip lebih luwes dan adaptif, serta tidak mengulang kembali rumusan elemen deskripsi. Keduanya adalah dua sisi dari satu uang koin.

\subsection{Entitas, atribut, dan relasi: Dari Records in Contexts kembali ke ISAD-G dan Dublin Core}

Pada Februari 2020, ICA resmi merilis kedua bagian dari Records in Contexts (RiC): A Conceptual Model for Archival Description dan An Ontology. Setelah hampir 8 tahun lamanya, Experts Group on Archival Description (EGAD), melanjutkan kerja Committee on Best Practices and Standards, bentukan ICA Programme Commission berhasil mempersiapkan “...suatu standar deskriptif yang menyelaraskan, menggabungkan, dan mengembangkan empat standar sebelumnya" (Pitti et al. 2014, 1). Standar terbaru ini merumuskan ulang apa yang dimaksud dengan "deskripsi arsip" dan menekankan pentingnya latar penciptaan dalam pengarsipan, sebagaimana tersurat pada penggunaan lema "records" pada judul dan pencantumannya dalam uraian, sehingga kelak berdampak pada akses sepanjang masa sekalipun pencipta arsip telah tiada.

Pembahasan berikut terdiri dari tiga bagian yang penulis anggap merupakan inti RiC. Penulis menggunakan kedua bagian RiC edisi terakhir. Ketiga uraian inti tersebut adalah entitas, atribut, dan relasi.

\section{A. Entitas}

Inilah yang penulis anggap sebagai pemaparan lanjutan "apakah fungsi itu". Melanjutkan semangat ISDF, RiC lebih lantang memaparkan "apakah entitas itu" dan bagaimana hubungannya dengan fungsi yang lebih dahulu didefinisikan. Pendekatan fungsi sebagaimana yang dipaparkan ISDF merupakan pengantar untuk memperkenalkan entitas pengarsipan kepada bukan ruang lingkup kearsipan. Fungsi menurut ISDF adalah: "Any high level purpose, responsibility or task assigned to the accountability agenda of a corporate body by legislation, policy or mandate. Functions may be decomposed into sets of co-ordinated operations such as subfunctions, business processes, activities, tasks or transactions".

Lebih lanjut, pengertian entitas terdapat dalam salah satu bagian dari ISO 23081 yang sebelumnya lebih dikenal dengan ICA Req(-uirements). Apakah berdiri sendiri, bergabung bersama, kembali berpisah dengan struktur yang lebih rendah daripada sebelumnya; ataukah hilang sama sekali; ataukah lalu hidup kembali dengan fungsi serupa. Fungsi pengarsipan sejatinya hidup lebih lama daripada struktur kelembagaan yang menjalankan fungsi itu sendiri. Arsip, baik records maupun archival records, dengan segala perubahan dan prosesnya, pun merupakan salah satu entitas. Entitas juga merupakan upaya menggantikan struktur atau setidaknya mengembalikan struktur sesuai fungsinya.

Entitas adalah "objek perhatian utama bagi praktisi yang mengelola arsip dalam konteks permulaan dan penggunaan bagi records managers, dan untuk preservasi jangka panjang dan akses 
bagi archivists". Ini bisa berarti apapun bagi kedua profesi tersebut. Bisa berarti elemen deskripsi, bisa juga berarti elemen metadata. Bisa berarti deskripsi jamak berjenjang (multilevel description), bisa juga berarti deskripsi jamak dimensi (multidimensional description). Perluasan unit deskripsi sebagaimana ISAD-G rumuskan semakin mudah terhubung, tidak hanya antarunit dalam suatu lembaga.

Sekalipun entitas tetap hierarkis, namun kedudukan dan pergerakannya sangat lentur, sama sekali tidak bergantung pada struktur kelembagaan. Terdiri dari empat tingkat (four levels of entities hierarchy). Bandingkan dengan tingkat dalam deskripsi jamak berjenjang. Sekalipun keempatnya terhubung secara hierarkis dan tetap menggunakan lema "level" sebagaimana deskripsi jamak berjenjang ISAD-G, relasi yang dihubungkannya tidak tunggal dan sederhana. Thing atau concept terletak dan satu-satunya entitas yang berada di tingkat pertama sehingga definisinya pun meluas, bisa berarti apapun bentukan manusia, seperti konsep, wacana, dan pengalaman bersama. "Sesuatu" inilah yang merupakan entitas akar atau dasar.

Pada tingkat kedua di bawah "sesuatu" terdapat record resource, instantion, agent, event, rule, date, dan place sebagai ketujuh entitas. Tidak semua entitas pada tingkat kedua memiliki entitas bawahan. Selain instantion dan place, kelima entitas lainnya membawahi beberapa entitas. Record resource membawahi record set, record, dan record part. Agent membawahi person, group, position, dan mechanism. Event hanya membawahi activity. Rule pun hanya membawahi mandate. Adapun date, yang juga merupakan elemen deskripsi wajib ISAD-G, mencakup single date, date range, dan date set. Pada tingkat keempat, group membawahi family dan corporate body. Record resource, instantion, agent, dan activity merupakan entitas inti, lebih sedikit daripada keenam elemen wajib (essential, mandatory) ISAD-G. Enam entities lebih sedikit daripada RiC-CM 1.0, RiC-CM 2.0 mencantumkan 8 entities. Kedelapan entities tersebut adalah thing, record resource, instantion, agent, event, rule, date, dan place. Thing menempati posisi tertinggi dan sendiri karena sebagaimana ucapan Barbara Reed bahwa arsip semakin lama semakin abstrak, semakin sulit memisahkan informasi dari medium yang memperantarainya.

\section{B. Atribut (dahulu Properti)}

Masing-masing atau sebagian entities membawahi sekian attributes, menurut RiC-CM 2.0, yang saling beririsan. Adapun RiC-CM 1.0 tidak menyebutnya sebagai attributes, melainkan properties. Selalu dalam nomina bentuk jamak, attributes membawahi atau, lebih tepatnya, menghubungkan titik-titik yang cakupannya lebih beragam daripada entities. Sekalipun beragam, attributes dapat merangkum banyak-apabila menggunakan kriteria ISAD-G-items di mana instansiasi memungkinkan tangkapan informasi tanpa bergantung pada medium perekaman.

Sebagaimana prinsip asal-usul, menurut paparan Bill Stockting (2017) yang masih menggunakan lema properties, attributes pun miliki dua dimensi: umum dan unik. Kiranya keduanya pun serupa dengan kriteria mendasar (essential, mandatory) dan tambahan (optional) dalam ISAD-G. Dimensi umum mencakup elemen deskripsi yang wajib ada pada setiap tingkat deskripsi, seperti nama (pelaku, pencipta, dan organisasi), tempat, dan tanggal. Dimensi unik mencakup elemen yang hanya ada pada organisasi tertentu, di kawasan tertentu, dan pada suatu waktu.

Sewaktu masih bernama properties, misalnya, record set memiliki 4 tema properties: content, carrier, representation, dan management and use. Ketika bernama attributes, record set merupakan salah satu dari tiga (record part dan record itu sendiri) pembentuk record resource. Ketiga pembentuk record resource tersebut harus memenuhi tiga nama atribut: descriptive note, identifier, dan name. Setiap atribut memiliki elemen deskripsi, seperti accrual, activity type, authenticity note, carrier extent, carrier type, certainty, classification, conditions of access, conditions of use, content type, coordinates, corporate body type, hingga bahasa dan technical characteristics. 


\section{Relasi}

Hubungan atau relasi yang RiC kembangkan berbeda dari keempat standar sebelumnya. Relasi bermodelkan bagan (graph model) seperti Resource Description Framework (RDF), bukan hierarki-struktural-tunggal. Relasi ini kelak mengubah sistem pengarsipan seturut EAD dan EAC, sebagaimana terdapat dalam RiC Onthology. Relasi ini pada waktu bersamaan lebih sederhana karena lebih luwes namun lebih rumit karena menghubungkan setiap tingkat perkembangan, korespodensi, pemberkasan, dan agregasi. Apa yang menjadi per tinggal bagi pengirim merupakan asli bagi penerima, dan merupakan tembusan bagi atasan serta salinan bagi siapa yang memerlukan. Apa yang menjadi bukti bagi salah satu atau bahkan kedua belah pihak, bisa jadi merupakan aset bagi pihak-pihak lain, bahkan merupakan informasi yang terbuka bagi pihak terdampak sekalipun tidak terlibat dan mungkin memberatkan posisi pihak-pihak yang terlibat. Secara retensi, bukti bisa musnah bagi satu pihak namun permanen bagi pihak lain.

Relasi berlangsung tidak hanya antarentitas dan antaratribut, tetapi juga antara entitas dan atribut serta sebaliknya. Tidak hanya menghubungkan kedua belah pihak, tetapi juga menghubungkan banyak pihak. Dalam RiC-CM 2.0, terdapat 13 corak relasi:

1. Relasi keseluruhan dengan setiap bagian (whole-part relations) sebagaimana pada deskripsi jamak berjenjang.

2. Relasi kelanjutan (sequential relations) antara satu agen dengan agen pelanjut, antara pencipta dengan penyimpan atau pemberi akses, dan antara wali (custody) dengan pencipta (creating agencies).

3. Relasi subjek (subject relations) antara arsip dengan pokok bahasan, antara series dengan files atau antara pemberkasan berkala dengan pemberkasan fungsi.

4. Relasi sesama record resource, seperti setiap tingkat perkembangan arsip yang saling terhubung.

5. Relasi record resource dengan instansiasi, seperti arsip bermediumkan kertas dengan bentuk konversi dan migrasinya atau hubungan alih media.

6. Relasi asal-usul (provenance relations), hubungan antara agen dengan arsip dengan kegiatan.

7. Relasi instansiasi, hubungan antara medium-medium yang melestarikan informasi dan akses.

8. Relasi manajemen, hubungan struktur jenjang pekerjaan dalam suatu organisasi.

9. Relasi antar-agen, hubungan keagenan yang memastikan setiap pelaku menangkap dan memberkaskan arsip.

10. Relasi kejadian, hubungan antara arsip dengan kejadian (event). Kejadian atau peristiwa berbeda dari kegiatan. Kejadian bersifat sekali terjadi, sedangkan kegiatan bersifat rutin. Relasi ini mengemuka pada sarana bantu temu kembali berbentuk guide.

11. Relasi aturan, hubungan antara agen dengan mandat.

12. Relasi waktu, hubungan antara record resource dengan tanggal.

13. Relasi spasial, hubungan antara tempat atau ruang dengan agen.

\subsection{Negara-negara dan entitas kearsipan nasional}

Bagian ini menguraikan secara singkat bagaimana lembaga kearsipan nasional di berbagai negara menerapkan elemen deskripsi dan metadata sebagaimana standar kearsipan mereka rumuskan. Standar tersebut terbit baik melalui upaya lembaga profesi setempat maupun bekerjasama dengan lembaga kearsipan nasional. Bermula dari penerjemahan Dutch Manual ke berbagai bahasa, setiap negara mulai mengadaptasi prinsip-prinsip pengolahan arsip dan menyusun standar kearsipan mereka sendiri. 
Sejatinya sekalipun berbeda-beda negara terbitnya, standar-standar kearsipan tersebut mengembangkan prinsip-prinsip yang serupa dan tidak membeda-bedakan arsip berdasarkan medium atau alat bacanya. Arsip adalah informasi, sekalipun tampilannya dapat saja berbeda. Pengertian arsip sepintas berubah, namun sejatinya maknanya tetap sama, baik sebagai "rekaman informasi", "informasi", maupun sebagai "representasi peristiwa" dalam berbagai bentuk, medium, dan format. Arsip tersebut harus diolah dan dikelola, tidak hanya disimpan namun juga diberikan kepastian akses sepanjang waktu.

Merujuk pada Manuel pour le Classement des Archives, Hilary Jenkinson (1922: 17 - 19, 79 - 97) menyatakan bahwa sekalipun banyak hambatan penyusunan pembakuan, seperti perbedaan lema dan istilah, tetapi selama prinsip-prinsip kearsipan dapat dipenuhi maka suatu standar nasional dapat disusun. Walau prinsip asal-usul merupakan "chief principle" penataan tetapi perhatian tertuju pada pencipta arsip bukan pada klasifikasi. Arrangement membawahi dua proses: sejarah dan organisasi Administrations, serta klasifikasi arsip ("classes, sub-division, and again sub-division"). Edisi terjemahan berjudul Manual for the Arrangement of the Archives merambah Amerika pada 1940 atas kerjasama Arthur H. Leavitt dengan Arnold J. F. van Leur. Sebelumnya Charles Hilary Jenkinson telah mengutip isi Dutch Manual dalam Manual of Archive Administration yang terbit pada 1922. Kedua prinsip tersebut diterjemahkan menjadi principle of provenance dan principle of original order. Belakangan, Theodore Roosevelt Schellenberg, sang arsiparis penilaian dan penyusutan, mengutip sebagian dari 100 aturan Dutch Manual dalam Modern Archives.

Arsiparis Kanada menyodorkan konsep "Total Archives". Sejak awal Abad XIX dua tugas utama arsiparis mulai dirumuskan: mengumpulkan dan melakukan akuisisi arsip statis. Sepanjang medio 1900 hingga akhir dasawarsa 1970-an, tugas tersebut bertambah: menata "organization's own record" dan melayani kepentingan sejarawan. Menurut Laura Millar (1998: 105 - 106), pada kurun inilah, "... the term "total archives" was first coined," menjelang Zaman Informasi. Perhatian pada informasi bukan pada media, bahwa arsip mencakup tidak hanya milik pemerintah tetapi juga pihak swasta dan masyarakat umum, bahwa arsip tidak hanya kertas, mulai mengemuka. Mengutip Millar, "brought the world of archives into the information world."

Sejak awal dasawarsa 1980-an, pengembangan konsep total archives berubah menjadi archival system. Identitas Ke-Kanada-an semakin dipertanyakan seiring keragaman masyarakat yang semakin pelik. Di masa lampau, prinsip "asal-usul" tidak pernah menjadi perhatian utama arsiparis Kanada karena sejarah kearsipan tidak beranjak dari pengelompokkan arsip berdasarkan penciptanya (apakah lembaga pemerintah ataukah bukan) dan tingkat perkembangan (apakah asli, kopi, salinan, ataukah tembusan), tetapi dokumen kesejarahan dalam bentuk apapun mengenai Kanada. Akan tetapi, apabila kita seksama perhatikan, perdebatan antara mereka yang menolak dengan mereka yang menerima, justru prinsip "asal-usul” seperti dilahirkan kembali di Kanada. Bahwa asal-usul informasi tidak kalah penting daripada asal-usul medium perantaranya. Sekalipun begitu pedoman kearsipan Kanada yang bertajuk Rules for Archival Description (RAD 1990/ 2008), menyatakan bahwa respect des fonds merupakan (http://www.cdncouncilarchives.ca/RAD/RAD Principles July2008.pdf, diakses pada 25 Mei 2018) “... the basis for arrangement and description" yang terdiri atas dua bagian "... provenance and original order." Lebih lanjut, "The principle of provenance demands that no records are excluded from description because of their particular form or medium. However, different media will require specific rules to accurately describe their unique characteristics. Rules for archival description must accommodate all media (and the relationships between them) within the body of records of one creator." Inilah kiranya yang disebut sebagai "reconceptualization of provenance" (Upward et al., 2011, 214). 
Di Inggris, Manual of Archival Description (MAD) telah rilis tiga kali: 1986, 1990, dan 2000. Menurut Michael Cook (1990, 133), MAD2 — edisi perluasan MAD1—berpusat pada koleksi pada suatu repositori yang bertujuan untuk menyusun sarana bantu temu kembali yang bersatu padu. Mengenai prinsip kearsipan, MAD2 menyatakan bahwa “...hanya akan terdapat satu sarana bantu temu kembali untuk setiap tempat penyimpanan dalam suatu susunan terstruktur yang melestarikan dan menjelaskan sistem awal yang menghasilkan arsip" ("proposes that there will be one principal finding aid for each repository in a structural order that preserves and explains the original system which produced the archives"). Sistem ini juga dikenal dengan “...organizationally-related groupings".

Describing Archives: A Content Standard (DACS 2004/2013, xv - xvi), pedoman kearsipan keluaran Council of the Society of American Archivists menyatakan, "How archives manage and describe their holdings is rooted in the nature of the materials, the context of their creation, and two hundred years of archival theory." Pernyataan ini menyiratkan keterkaitan antara kearsipan sebagai praktek dan teori (ilmu). Terdapat delapan prinsip yang melandasi DACS. Prinsip pertama dan kedua dari DACS, terkait respect des fonds, seraya mengutip dan mengembangkan gagasan dalam Dutch Manual, terdapat pernyataan: "The records created, assembled, accumulated, and/or maintained and used by an organization or individual must be kept together (i.e., identified as belonging to the same aggregation) in their original order, if such order exists or has been maintained. They ought not to be mixed or combined with the records of another individual or corporate body." Respect des fonds menaungi dua sub-prinsip: provenance dan original order. Provenance berarti bahwa "... the records must be clearly reflected in the description, that the description must enable retrieval by provenance, and that a descriptive system must be capable of representing together all the records of a single creator held by a single repository." Bagian Pertama DACS terdiri dari delapan bab mirip dengan kedelapan elemen ISAD-G. Berbeda dengan Dutch Manual, DACS menguraikan jelas definisi dari arrangement dan description. Arrangement adalah proses dan hasil pengelompokkan dokumen menurut prinsipprinsip kearsipan yang disepakati ("...the intellectual and/or physical processes of organizing documents in accordance with accepted archival principles, as well as the results of these processes"). Adapun description adalah penciptaan representasi materi kearsipan yang akurat melalui proses ("...the creation of an accurate representation of the archival material by the process of capturing, collating, analyzing, and organizing information that serves to identify archival material and to explain the context and records systems that produced it, as well as the results of these processes").

Arsiparis Australia mengemukakan dua ragam baru prinsip asal-usul: bersamaan-jamak (simultaneous-multiple) dan paralel. Perbedaan keduanya terletak pada kesediaan atau ketidaksediaan suatu meta-system. Kesamaan keduanya terletak pada kesediaan menerima keragaman sudut pandang serta perbedaan fungsi dan kepentingan (Upward, et.al., 2011: 201, 220). Inilah yang kemudian lebih kita kenal sebagai Australian Series System (Smith, 1995). Pada 2007 Australian Society of Archivists (ASA) mengeluarkan Describing Archives in Context: A Guide to Australasian Practice (DAiC) yang kembali menegaskan penerapan Australian Series System. Latar inilah yang memengaruhi penyusunan pedoman kearsipan terbaru ICA.Series System. Latar inilah yang memengaruhi penyusunan pedoman kearsipan terbaru ICA.

Akhmadsyah Naina (2008, 89-90) tidak menanggapi secara kritis ISAD-G. Naina memahaminya untuk diterapkan dalam penyusunan sarana bantu temu kembali dan pengembangan Jaringan Informasi Kearsipan Nasional (JIKN) ANRI. Noerhadi Magetsari $(2008,8)$ beranggapan bahwa Dutch Manual merupakan "buku prinsip-prinsip kearsipan modern" Indonesia. Sependek pengetahuan saya, Magetsari-lah yang pertama kali menuliskan dan mengutip Dutch Manual meskipun tidak menguraikan lebih lanjut mengenai prinsip-prinsip kearsipan yang termaktub di 
dalamnya. Pada Desember 2011, ANRI melalui Pusat Kajian dan Pengembangan Sistem Kearsipan merilis Pedoman Pengolahan Arsip Statis dalam Penyelenggaraan Jaringan Informasi Kearsipan Nasional, tanpa mencantumkan rujukan sama sekali namun isinya jelas merujuk pada ISAD-G, menyatakan bahwa kendali terhadap khazanah arsip yang Lembaga Kearsipan simpan di repositori meliputi dua hal: administrasi dan intelek. Mengenai prinsip kearsipan, Pedoman menyatakan bahwa "Prinsip respect des fonds terdiri dari dua konsep terkait: asal-usul dan aturan asli. Asalusul mengacu pada "lembaga asal" arsip (pencipta arsip); aturan asli mengacu pada aturan dan pengorganisasian dokumen yang diciptakan serta disimpan oleh lembaga asalnya" (ANRI 2011, 5). Pada Desember 2016, Direktorat Pengolahan selesai menyusun Standar Deskripsi Arsip Statis (SDAS). Hanya saja, pengertian asal-usul dan aturan asli masih menurut pemikiran akhir abad XIX, tidak mengikuti perkembangan wacana kearsipan di dunia. Mengutip glossarium dari Society of American Archivist (SAA), asal-usul adalah “....arsip dari asal yang berbeda-beda disimpan terpisah sesuai dengan asalnya untuk melestarikan konteksnya," dan aturan asli adalah "...arsip harus diatur dalam suatu sistem yang q (ANRI 2016, 1, 8, 12 - 14). Secara tersurat tidak terdapat rujukan Dutch Manual, baik edisi aslinya maupun edisi berbahasa Inggris, di daftar pustaka. Prinsip-prinsip tersebut diterjemahkan dari frasa Bahasa Perancis (respect des fonds, respect de l'ordre interieur) dan Bahasa Inggris (principle of provenance, respect for original order), bukan Bahasa Belanda (SDAS 2016, 14).

\subsection{Relasi antar-elemen serta kerangka dan elemen kerjasama}

Sebagaimana keterhubungan keduapuluh enam elemen deskripsi dan kelimabelas elemen metadata, pada dasarnya relasi bergerak tidak hanya secara berjenjang dari luas ke sempit dan dari atas ke bawah, namun relasi juga bergerak secara tersebar dan menyebar (poly-hierarchical). Selain "terhubung dengan" dan "mengandung" informasi, relasi juga menangkap "bagian dari" dan merupakan "bawahan dari" atau merupakan "atasan dari" yang terus berubah dan bergerak. Inilah peralihan kerja deskripsi dari "jamak berjenjang" (multi-level description) ke "dimensi jamak" (multi-dimensional description). Elemen-elemen deskripsi dan metadata mengaitkan setiap entitas serta satuan di bawahnya, baik berupa atribut maupun berupa kelas.

Paradigma Integrasi-Interkoneksi (Interkon) tergambar seperti jejaring laba-laba merupakan gagasan yang Muhammad Amin Abdullah, Guru Besar Universitas Islam Negeri Sunan Kalijaga Yogyakarta. Kembangkan sejak awal 2000. Sekalipun Abdullah menggagasnya sebagai bentuk keterbukaan dan keterkaitan khazanah ilmu-ilmu keislaman dengan ilmu-ilmu umum, namun paradigma tersebut dapat diterapkan untuk menggambarkan keterkaitan dan persatuan rumpun keilmuan lain. Tidak mungkin mengamati, menganalisa, dan menyimpulkan suatu fenomena atau peristiwa dari satu perspektif keilmuan. Maka dari itu Abdullah menawarkan perspektif keberagaman melalui pendekatan lintas disiplin.

Pada akhir 2020, Abdullah melengkapi paradigma tersebut melalui ketiga tahap pendekatan. Hubungan ketiganya merupakan suatu tahapan, bukan hanya sekadar pilihan. Secara berturut-turut ketiganya mencakup multidisiplin, interdisiplin, dan transdisiplin. Pada tahap pertama, suatu penelitian menggunakan berbagai pendekatan namun setiap pendekatan tetap menjaga jaraknya. Pada tahap kedua, suatu penelitian dilakukan bersama namun setiap pendekatan bekerja sesuai disiplin dan metode masing-masing. Pada tahap ketiga, dua atau lebih disiplin bersatu bahkan lebur untuk menghadirkan ilmu baru. Dari ketiganya, tahap kedua dapat menjadi titik mula kerjasama rumpun bidang galleries, libraries, archives, and museums (GLAM) sehingga lebur pada tahap ketiga menjadi ilmu informasi, misalnya. 


\section{KESIMPULAN: BERBEDA-BEDA DISIPLIN SATU ELEMEN METADATA JUA}

Informasi-lah yang menghubungkan antara arsip dan metadata sehingga keduanya begitu serupa. Apabila arsip adalah informasi yang merepresentasikan peristiwa, maka metadata adalah informasi yang memampukan arsip beralih media dari satu medium ke medium lain, dari satu format ke format lain, dan dari satu bentuk ke bentuk lain. Tanpa metadata maka arsip analog, elektronik, dan digital kehilangan konteks. Tanpa deskripsi, arsip kertas kehilangan konteks.

Metadata adalah deskripsi baru, namun tidak begitu baru atau bahkan sama sekali tidak baru kecuali berbeda waktu kemunculannya dan bagi sebagian besar kalangan berbeda medium pengarsipannya. Elemen-elemen deskripsi seakan-akan hanya untuk arsip bermediumkan kertas, sedangkan elemen-elemen metadata seakan-akan hanya untuk arsip bermediumkan elektronik, analog, dan digital. Akan tetapi apabila arsip adalah representasi peristiwa atau informasi yang berdasarkan pada proses maka kerja deskripsi diterapkan pada arsip sekalipun mediumnya berbeda-beda dan terus berubah. Telah terjadi perubahan dari metadata deskriptif ke metadata konteks, bukan hanya metadata berdasarkan medium dan agensi.

Kerjasama antarilmu baik dalam satu maupun berbeda rumpun hanya dapat terjadi apabila kedudukan setiap ilmu sejajar. Kesejajaran antarilmu dapat diawali dengan memahami keunikan setiap lema yang digunakan dan menemukan kesejatian kesamaan dalam definisi sekalipun berbeda lema, kata kunci, dan frasa. Apabila itu semua telah dilakukan para praktisi setiap keilmuan maka tersedia salah satu dari tiga tahap, bukan pilihan, kerjasama antardisiplin: apakah multi-, inter-, ataukah transdisiplin.

Kerjasama serumpun hanya dapat terjadi apabila setiap ilmu di dalamnya bersedia berbagi pemahaman serupa dengan lema yang berbeda-beda namun substansi definisi yang serupa untuk mencapai tujuan yang sama, misalnya memberikan akses terhadap informasi yang dikelola. Tidak ada pemaksaan suatu lema salah satu ilmu terhadap ilmu-ilmu serumpun. Kerendahan hati para praktisi merupakan keharusan untuk menenggang rasa. Keberadaan mata kuliah kearsipan di beberapa fakultas berbeda memperlihatkan keluwesan Ilmu Kearsipan. Sekalipun Ilmu Kearsipan jamak dikenal di Indonesia sebagai ilmu terapan, tidak lantas ilmu tersebut tidak memiliki prinsipprinsip keilmuan yang unik. Keunikan ini pun tidak lantas menutup kerjasama dengan bidangbidang keilmuan serumpun dan bidang-bidang lain. Sebagaimana ilmu kearsipan, setiap ilmu pun unik. Di balik keragaman lema bersemayam keserupaan pengertian, bahkan sekalipun lema tersebut sama antara satu ilmu dengan ilmu lain, tetap saja terdapat pengertian yang berbeda, maka penghormatan adalah jalan terbaik. Tidak perlu lagi ada pemilahan ilmu-ilmu bantu (auxiliary sciences) dan ilmu-ilmu utama (main sciences). Kecuali kepentingan pengajaran dan pendidikan, tidak perlu ada pemilahan ilmu-ilmu terapan dan ilmu-ilmu murni. Seperti elemen-elemen deskripsi dan metadata yang saling terkait dan menjelaskan keseluruhan konteks dan representasi suatu peristiwa, setiap ilmu pun saling terhubung untuk saling melengkapi penjelasan terhadap suatu peristiwa. Keilmuan monodisiplin adalah "intelectual suicide", demikian ucap Abdullah pada 2 November 2020 dalam webinar yang Maarif Institute selenggarakan (https://www.youtube.com/watch?v=IHEvszPqp1A, diakses pada 12 September 2021).

\section{PERNYATAAN TERIMA KASIH}

Penulis harus berterima kasih kepada Himpunan Mahasiswa Kearsipan Indonesia (HMKI) yang berkenan mengundang penulis pada salah satu dari sekian webinar rutin yang mereka adakan. Paparan penulis dalam webinar tersebut dan pertanyaan partisipan yang mengiringinya merupakan bahan dasar pembentuk tulisan ini. Penulis juga berterima kasih kepada Peminatan Kearsipan Magister Ilmu Perpustakaan dan Informasi dan Program Studi Strata 1 Departemen Ilmu Perpustakaan dan Informasi Universitas Indonesia yang berikan penulis kesempatan mengajar 
mata kuliah Manajemen Arsip, Retensi, dan Administrasi Arsip. Kepada kedua komite teknis (0103 Kearsipan dan 01-05 Dokumentasi dan Informasi) yang penulis terlibat di dalamnya, penulis perlu juga berterima kasih. Terakhir, penulis berterima kasih kepada teman-teman di Pusat Pengkajian dan Pengembangan Sistem Kearsipan dan Pusat Data dan Informasi Deputi Bidang Informasi dan Pengembangan Sistem Kearsipan Arsip Nasional Republik Indonesia serta Direktorat Pengolahan Deputi Bidang Konservasi yang memberikan kesempatan kepada penulis untuk memahami prinsip dan standar kearsipan, serta menyusun beberapa pedoman kearsipan.

\section{BIBLIOGRAFI}

Abdullah, Muhammad Amin. 2021. Multidisiplin, Interdisiplin, dan Transdisiplin: Metode Studi Agama dan Studi Islam di Era Kontemporer. Yogyakarta: IB Press.

Arsip Nasional Republik Indonesia. 2011. Pedoman Pengolahan Arsip Statis dalam Penyelenggaraan Jaringan Informasi Kearsipan Nasional. Jakarta: Pusat Pengkajian dan Pengembangan Sistem Kearsipan.

-----. Peraturan Arsip Nasional Republik Indonesia 14/2018 tentang Standar Deskripsi Arsip Statis.

Australian Society of Archivists. 2017. Response of the Australian Society of Archivists to the International Council of Archives Expert Group on Archival Description Records in ContextConceptual Model. Australia: Australian Society of Archivists.

Canadian Commitee on Archival Description of the Canadian Council of Archives with the National Archives of Canada. 2008. Rules for Archival Description. Canada: National Archives of Canada.

Cook, Michael. 1990. "The British Move Toward Standards of Archival Description: The MAD Standard." American Archivist 53:130-138.

Cook, Terry. 1997. "What is Past is Prologue: A History of Archival Ideas since 1898, and the Future Paradigm Shift." Archivaria 43:17-63.

Council of the Society of American Archivists. 2013. Describing Archives: A Content Standard. Second edition. Chicago: The Society of American Archivists.

Den Teuling, A. J. M. 2003. Archiefterminologie voor Nederland en Vlaanderen. 's Gravenhage: Stichting Archiefpublicaties.

Evans, Joanne. Sue McKemmish. Barbara Reed. 2009. "Making Metadata Matter: Outcomes from the Clever Recordkeeping Metadata Project." Archives and Manuscripts 37 (1):28-56.

Clavaud, Florence. 2017. "Presentation of Records in Contexts: Ontology," Records in Contexts. Diakses pada 12 September 2020. https://www.youtube.com/watch?v=ocAO ghQ0ED8.

Furner, Jonathan. 2016. "Records in Context" in Context: A Brief History of Data Modelling for Archival Description," Unpublished paper. Second draft. Diunduh pada 3 Maret 2020. http://www.jonathanfurner.info/?page_id=15.

Horsman, Peter; Eric Ketelaar and Theo Thomassen. 2003. Introduction to the 2003 Reissue: v xxxiii, in Manual for the Arrangement and Description of the Archives: Drawn up by the Direction of the Netherlands Association of Archivists. Samuel Muller, Johan Feith and Robert Fruin (eds.). Chicago: the Society of American Archivists.

International Council on Archives. 2000. General International Standard Archival Description. Second Edition. Paris: International Council on Archives.

-----. 2004. International Standard Archival Authority Record for Corporate Bodies, Persons and Families. Second Edition. Paris: International Council on Archives.

-----. 2007. International Standard for Describing Functions. First Edition. Paris: International Council on Archives.

-----. 2008. International Standard for Describing Institutions with Archival Holdings. First Edition. Paris: International Council on Archives.

----- 2015. Records in Contexts: An International Standard for Archival Description, Progress Report. Cleveland: International Council on Archives.

-----. 2016. Records in Contexts: A Conceptual Model for Archival Description. Paris: ICA Consultation Draft.

----. 2019. Records in Contexts: Ontology. $1^{\text {st }}$ Version. Paris: International Council on Archives. 2019. 
International Organization for Standardization. 2017. 23081 - 1: Information and documentation Records management processes - Metadata for records - Part 1: Principles. Jenewa: ISO.

----. 2009. 23081 - 2 Information and documentation - Managing metadata for records - Part 2: Conceptual and implementation issues. Jenewa: ISO.

----- 2016. 15489 - 1. Information and documentation - Records management - Part 1: Concepts and principles. Jenewa: ISO.

-----. 2017. 15836 - 1. Information and documentation - The Dublin Core metadata element setPart 1: Core elements. Jenewa: ISO.

----. 2019. 15836 - 2. Information and documentation - The Dublin Core metadata element setPart 2: DCMI Properties and classes. Jenewa: ISO.

Jenkinson, Hilary. 1922. A Manual of Archive Administration Including the Problems of War Archives and Archive Making. Oxford: Clarendon Press.

Magetsari, Noerhadi. 2008. "Organisasi dan Layanan Kearsipan." Jurnal Kearsipan 3 (1):1-17.

McKemmish, Sue. Glenda Acland. Nigel Ward. Barbara Reed. 1999. "Describing Records in Context in the Continuum: The Australian Recordkeeping Metadata Schema." Archivaria Fall 48:3-37 (bisa juga diakses di http://staginginfotech.monash.edu.au/research/groups/rcrg/publications/archiv01.html, diakses pada 3 Maret 2020).

Millar, Laura. 1998. "Discharging Our Debt: The Evolution of the Total Archives Concept in English Canada." Archivaria 46:103-146.

Muller, Samuel. 1920. Johan Feith and Robert Fruin (eds.). 2e editie. Handleiding voor het Ordenen en Beschrijven van Archieven. Groningen: Erven B. van der Kamp.

Naina, Akhmadsyah. 2008. "Mengenal General International Standard Archival Description." Jurnal Kearsipan 3 (1):84-102.

Pitti, Daniel. 2017. "Presentation of Records in Contexts," Records in Contexts. Diakses pada 12 September 2020. https://www.youtube.com/watch?v=YcoosGnrlsI\&pbjreload=101.

Shepherd, Elizabeth and Charlotte Smith. 2000. "The Application of ISAD(G) to the Description of Archival Datasets." Journal of the Society of Archivists 21 (1):55-86.

Smith, Clive. 1995. "Australian Series System." Archivaria 40:86-93.

Stockting, Bill. 2017. "Presentation of the Conceptual Model." Records in Contexts. Diakses pada 12 September 2020. https://www.youtube.com/watch?v=b0xSIzeCvlI.

----. Diakses pada 28 Mei 2021. https://www.youtube.com/watch? $\mathrm{v}=\mathrm{rMgFPES01Rs} \& \mathrm{t}=2102 \mathrm{~s}$.

-----. Diakses pada 12 September 2021. https://www.youtube.com/watch?v=IHEvszPqp1A.

Upward, Frank. Sue McKemmish. Barbara Reed. 2011. "Archivists and Changing Social and Information Spaces: A Continuum Approach to Recordkeeping and Archiving in Online Cultures." Archivaria 72:197-237. 